\title{
Physical chemical characterization of historical mining waste and ARD prediction tests
}

\author{
Antoneta Filcenco-Olteanu ${ }^{1,{ }^{*}, \text { Lena Alakangas }}{ }^{2}$, Antoio Fiuza $^{3}$, Marius Zlagnean ${ }^{1}$, and Nicolae Tomus ${ }^{1}$ \\ ${ }^{1}$ Research and Development National Institute for Metals and Radioactive Resource, 70,Carol I, Bvd, Bucharest, Romania, \\ ${ }^{2}$ Luleå University of Technology, Department of Civil, Environmental and Natural Resources Engineering, Porsön, University area, Luleå \\ Sweden \\ ${ }^{3}$ University of Porto, Engineering Faculty, Rua Dr. Roberto Frias, 4200-465 Porto, Portugal
}

\begin{abstract}
There are thousands of historical mine tailings and metallurgical residues present on inactive metal mining sites which have been abandoned. However, the potential release of dissolved metals, acidity, or suspended particulates from mine-waste dumps can be a serious and long-lasting problem. A variety of environmental impacts may occur at this abandoned mine sites and leading the list is acid generation, which is one of the main problems from metal mining. The objective of the present study was to characterize and evaluate the Romanian historical tailing of Sasar-Red Valley, near Baia Mare. This involved physical and chemical characterization of the materials and its acid generating potential. Sasar tailing impoundment contains 8.5 million $\mathrm{m}^{3}$ of tailings and occupies an area of 32.5 hectares. Tailings samples were collected from different depths in three sampling points, and characterized by grain size, chemical elements concentration, elements distribution of elements in depth, paste $\mathrm{pH}$, acid-base account and net acid generation tests. Acid base accounting (ABA) tests in conjunction with net acid generation (NAG) tests classified the samples into the category of 'potentially acid generating'. This paper presents a synthesis of works performed in the Improve Resource Efficiency and Minimize Environmental Footprint (REMinE) project.
\end{abstract}

\section{Introduction}

The key to future sustainable mining activities is resource efficiency and a holistic approach to the environmental consequences that can emerge during the mine's life, and should be based on the best-available techniques to minimize these consequences. In a long-term perspective, in combination with a more efficient extraction of minerals and metal, this could prevent the environmental impact. High content of metals and minerals in historical tailings and waste rock dumps, due to the earlier lack of efficient methods for extraction or low economical profitable at that time, could in many cases be a potential risk for environmental impact. However, certain minerals could also be resources contributing to the supply of metals and minerals to the market or could be utilized as a raw material for construction purposes.

Situated at Romania's northern border, Baia Mare, from Maramures County has been an important mining region for more than 2,500 years thanks to its abundant mineral resources. [1]

Baia Mare, Baia Sprie and Cavnic were the major ore deposits, which consist mainly of gold-bearing argentiferous galena and in some deposits gold, known in paragenesis with stibnite. [2]

\footnotetext{
* Corresponding author: antonetafilcenco@yahoo.ro
}

There are also approximately 215 tailings dams and ponds, several ore processing facilities and copper and lead smelters as well as a sulphuric acid plant. Over the years, the industrial activity was pursued with improper waste management, treatment and disposal. [3]

The mining wastes, from Baia Mare region cause a series of major environmental damage due to their large volumes and also due to their inherent danger, such as the potential of generating acid waters, high concentrations of heavy metals and the existence of hazardous substances from ore processing. Therefore, the reprocessing, removal and safe disposal of mining, processing and metallurgical wastes were encouraged to ensure an environmental improvement area. [4]

Solid wastes (waste rocks and concentrator tailings), which often contain sulfide minerals, can generate acidic discharges known as acid mine drainage (AMD) or acid rock drainage (ARD) after exposure to atmospheric conditions (air and water). ARD is typically characterized by low $\mathrm{pH}(\mathrm{pH}<5)$ and high levels of potentially toxic metals and sulphates $[5,6]$. These contaminants remobilize under acidic conditions and migrate into the water zone and groundwater system. [7]

Static tests are geochemical analyses of sulfidic waste which are used to predict potential of waste sample to produce acid. Details on these tests are documented in the literature [8-16]. 
Static tests, also called acid-base accounting (ABA) tests, are widely used to predict ARD because they are simple, inexpensive, and their results are rapidly obtained. ABA methods are also used for classifying samples according to their acid forming potential. $[7,9,10]$

The acid-base account involves static laboratory procedures that evaluate the balance between acid generation processes (oxidation of sulphide minerals) and acid neutralising processes (dissolution of alkaline carbonates, displacement of exchangeable bases, and weathering of silicates). Results are expressed as a net acid producing or acid consuming capacity per mass unit of rock. In addition, static tests and reporting convention vary. In Australia and the Asia Pacific region the ABA test is reported as a Net Acid Producing Potential (NAPP) value in units of $\mathrm{kg} \mathrm{H}_{2} \mathrm{SO}_{4} / \mathrm{t}$ and the values arising from the acid-base account are referred to as the maximum potential acidity (MPA) and the acid neutralizing capacity (ANC), respectively. In North America, ABA results equivalent to NAPP are normally expressed as a Net Neutralization Potential (NNP) in units of $\mathrm{kg} \mathrm{CaCO}_{3} / \mathrm{t}$. The components in the calculation are the same, with the maximum potential acidity (MPA) normally expressed as AP (acid potential), and ANC expressed as NP (neutralizing potential). [17]

The objective of the present study was to characterize and evaluate the Romanian historical tailing Sasar-Red Valley, located near Baia Mare. This involved physical chemical characterization of the tailing samples collected from various depths by: grain size, chemical elements concentration, elements distribution in depth and its acid generating potential by means of paste $\mathrm{pH}$ acid-base accounting (ABA) tests and net acid generation (NAG) tests.

\section{Materials and methods}

\subsection{Study area}

The Maramures Country, situated at northern border of Romania with Ukraine, encloses the old "lands" of Maramures-Chioarul, Lapus and Baia Mare Basin.

Baia Mare Basin is a contact basin that interposes between the Somesana Plain and the Carpathian Mountains as a lower morphological unit, from the surrounding areas, presenting a waved surface, characterized by a convergent system of valleys and interfluves. It was formed due to the tertiary tectonic movement that took to the fragmentation and sinking of the crystalline in the North-Western part of Transylvania, as well as due to the volcanic chain of the Gutin-Oaş Mountains [4, 18].

The area belongs to the undifferentiated Quaternary characterized by deluvial deposits, andesitic blocks and alluvial deposits. Under the action of the external agents the andesites were altered and eroded and formed alluvial and deluvial deposits that make the transition from the deposits of Sasar River upper terrace. The sedimentary in Baia-Mare Basin is represented by grey-purple marls, clay marls and sands with sandstone horizons. [19]
The activities of extraction, processing and preparation of complex ore from the mining basin Baia Mare, left behind tens of dumps and mine tailings ponds, located mainly in the river valleys from this area.

The Sasar (Red Valley) tailing pond (presented in Fig. 1), located in the west part of Baia Mare, secured the storage of flotation tailings from the Processing Plant which was closed in 1982. It contains around 8.5 million $\mathrm{m}^{3}$ of fine grained waste ores embodying the acidic water producing mineral pyrite.

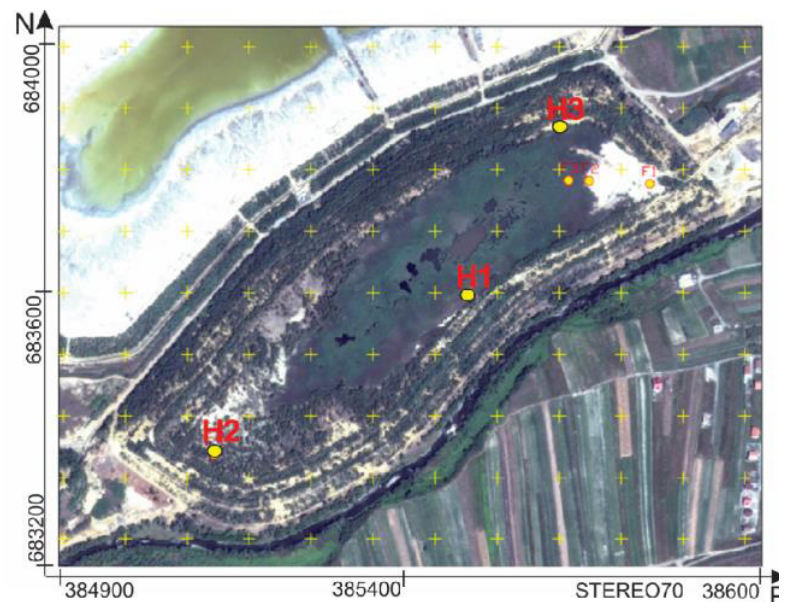

Fig. 1. The Sasar tailing impoundment and sampling points.

From mineralogical point of view, the tailings disposed in the Sasar tailing pond contain silicates (from the amphiboles and pyroxenes), sulphide minerals (pyrite, $\mathrm{FeS}_{2}$, chalcopyrite, $\mathrm{CuFeS}_{2}$, arsenopyrite, FeAsS, pyrrhotite, $\mathrm{Fe}_{(1-\mathrm{x})} \mathrm{S}$, marcasite, $\mathrm{FeS}_{2}$, jamesonite, $\mathrm{Pb}_{4} \mathrm{FeSb}_{6} \mathrm{~S}_{14}$, galena, $\mathrm{PbS}$, sphalerite, $\mathrm{ZnS}$ ) etc., other metallic minerals like oxides, hydroxides, as hematite, $\mathrm{Fe}_{2} \mathrm{O}_{3}$, specularite, rarely ilvaite, $\mathrm{CaFe}_{22}+\mathrm{Fe}_{3}+\left[\mathrm{OOH} \mathrm{Si} \mathrm{O}_{7}\right]$, oxi-hydroxi - iron sulphides (HOF), mineral associations (muscovite), clay minerals, carbonates and some secondary minerals (goethite, $\alpha-\mathrm{FeO}(\mathrm{OH})$, hematite $\left.\mathrm{Fe}_{2} \mathrm{O}_{3}\right)$. [20]

\subsection{Sampling}

Three sampling points were selected within tailing impoundment $\mathrm{H} 1$ central, $\mathrm{H} 2$ and $\mathrm{H} 3$ at the edges. (Figure 1) Drill samples were taken in September 2016 from Sasar impoundment and were preserved in polyethylene bags, transported and processed separately. The samples were taken with a soil auger from six depth intervals: $0-1 \mathrm{~m}$, 1-2 $\mathrm{m}, 2-3 \mathrm{~m}, 3-4 \mathrm{~m}, 4-5 \mathrm{~m}$ and 5-6m.

Prior to analysis, the samples collected were split with a riffle splitter, and half of each sample was kept for potential future analysis.

\subsection{Experimental methodology}

A size analysis of the samples was performed to determine the size distribution of the tailings samples and the content of gold, silver, iron, calcium and sulphur, for each depth interval. Grain size distribution of tailing 
samples was measured by standard wet sieving for 2-0.04 $\mathrm{mm}$ fraction, in combination with a laser granulometric analyser type Eye Tech Anchersmid. Cumulative grain size distribution was employed to calculate $\mathrm{D}_{50}$ (passing diameter which allow to pass $50 \%$ of the sample weight).

The bulk chemical composition of the samples was analysed with a Perkin Elmer Optima 3100 RL ICP-AES.

The sample moisture content was determined by drying $10 \mathrm{~g}$ soil samples at $105^{\circ} \mathrm{C}$ for $24 \mathrm{~h}$.

Static geochemical tests provide the basis for understanding potential reactivity and therefore ARD potential of a sample. The static geochemical tests were performed on pulverized samples $(<75 \mu \mathrm{m})$ collected from drill 3 from $1 \mathrm{~m}, 3 \mathrm{~m}$ and $6 \mathrm{~m}$ depth.

The paste $\mathrm{pH}$ and electrical conductivity (EC) measurements are good indicators of the immediate acidbase reactivity of a sample. This is demonstrated by comparison to other standard geochemical tests such as single addition net acid generation (NAG) test [22]. The paste $\mathrm{pH} / \mathrm{EC}$ was determined by equilibrating the sample in deionised water for approximately 12 hours at a solid to water ratio of $1: 2(\mathrm{w} / \mathrm{w})$ and then measuring the $\mathrm{pH}$ and EC. The paste $\mathrm{pH} / \mathrm{EC}$ was measured by a multi-parameter system Consort C832 calibrated against standard buffers at 4.01 and $7.0 \mathrm{pH}$. This gives an indication of the inherent acidity and salinity of the waste material when initially exposed in a waste emplacement area.

The net acid production potential (NAPP) is a measure of the samples overall acid generating capacity. It represents the balance between the capacity of a sample to generate acid (MPA) and its capacity to neutralise acid (ANC). NAPP (Equation 2) is the difference between the inherent acid neutralization capacity (ANC) and the maximum potential acidity (MPA) of the sample.

$$
N A P P\left(\frac{\mathrm{kg} \mathrm{H}_{2} \mathrm{SO}_{4}}{t}\right)=M P A-A N C
$$

A negative NAPP indicates that the sample has a net neutralizing capacity and a positive NAPP indicates that the sample has a net acid generating capacity [22].

MPA is based on total $\mathrm{wt} \% \mathrm{~S}$ as determined by LECO analysis [23] multiplied by the stoichiometric conversion factor 30.6, using the following formula:

$$
\operatorname{MPA}\left(\frac{\mathrm{kg} \mathrm{H}_{2} \mathrm{SO}_{4}}{t}\right)=(\text { Total } \% S) * 30.6
$$

The calculation assumes that the measured sulphur content occurs as pyrite $\left(\mathrm{FeS}_{2}\right)$ and that pyrite reacts under oxidizing conditions to generate acid according to the reaction:

$$
\mathrm{FeS}_{2}+15 / 4 \mathrm{O}_{2}+7 / 2 \mathrm{H}_{2} \mathrm{O} \rightarrow \mathrm{Fe}(\mathrm{OH})_{3}+2 \mathrm{H}_{2} \mathrm{SO}_{4}
$$

The acid neutralization capacity (ANC) of the studied samples was determined using the modified Sobek et al. [14] static test. With this method, approximately $0.5 \mathrm{~g}$ of the sample is tested for its fizz rating by the addition of a few drops of 1:3 $\mathrm{HCl}$ hydrochloric acid $(\mathrm{HCl})$. The resulting fizz (denoted by none, slight, moderate, or strong) determines the volume and the normality of $\mathrm{HCl}$ to be added to a $2 \mathrm{~g}$ sample for ANC determination. Also, blank samples were prepared by pipetting the same volume and concentration of acid into clean bakers containing deionized water. Digestion is achieved by heating the sample at $90^{\circ} \mathrm{C}$ until gas bubbling stops. Afterwards, the solution and "blank" samples were backtitrated with $\mathrm{NaOH}$ to $\mathrm{pH} 7.0$ to determine ANC of the sample. The amount of acid consumed by reaction with the sample is then calculated using the following formula: [22].

$$
A N C\left(\frac{k g H_{2} \mathrm{SO}_{4}}{t}\right)=\left[Y x M_{H C l} / w t\right] x C
$$

Where:

$\mathrm{Y}=($ Vol. of $\mathrm{HCl}$ added $)-($ Vol. of $\mathrm{NaOH}$ titrated $\mathrm{x} \mathrm{B})$ $\mathrm{B}=(\mathrm{Vol}$. of HCI in blank $) /(\mathrm{Vol}$. of $\mathrm{NaOH}$ titrated in blank)

$\mathrm{M}_{\mathrm{HCl}}=$ Molarity of $\mathrm{HCl}$

$\mathrm{wt}=$ Sample weight in grams

$\mathrm{C}=$ Conversion factor:

$\mathrm{C}=49.0$ (to calculate $\mathrm{kg} \mathrm{H}_{2} \mathrm{SO}_{4} / \mathrm{t}$ )

$\mathrm{C}=5.0$ (to calculate $\% \mathrm{CaCO}_{3}$ equivalent)

The single addition NAG test is used in association with the NAPP to classify the acid generating potential of a sample. This test involves the addition of $250 \mathrm{ml} 15 \mathrm{vol}$ $\% \mathrm{H}_{2} \mathrm{O}_{2}$ to $2.5 \mathrm{~g}$ of pulverized sample $(<75 \mu \mathrm{m})$, to encourage the rapid oxidation of reactive sulphides. The peroxide is allowed to react with the sample overnight and the following day the sample is gently heated to accelerate the oxidation of any remaining sulphides, then vigorously boiled for several minutes to decompose residual peroxide. When cool, the $\mathrm{pH}$ and acidity of the NAG liquor are measured. This $\mathrm{pH}$ measurement is referred to as the NAGpH. The acidity of the liquor is then used to estimate the net amount of acid produced per unit weight of sample. An indication of the form of the acidity is provided by initially titrating the NAG liquor to $\mathrm{pH} 4.5$ (NAGpH4.5), then continuing the titration up to $\mathrm{pH} 7$ (NAG). The titration value at a $\mathrm{pH}$ of 4.5 includes acidity due to free acid (i.e. $\mathrm{H}_{2} \mathrm{SO}_{4}$ ) as well as soluble iron. The titration value at $\mathrm{pH} 7$ also includes metallic ions that precipitate as hydroxides at $\mathrm{pH}$ 's between 4.5 and 7 .

The reagents used were chemically or analytically pure (to perform the analysis) and used without additional treatment.

\section{Results and discussion}

\subsection{Weathering profile characteristics}

In Sasar impoundment three zones were identified: an upper oxidation zone (reddish-brown-yellow coloured, acid generation and metal release), a hardpan layer (acid neutralization and metal accumulation) and a reduction zone (grey coloured, limited water movement, low oxygen diffusivity). The terms oxidized / unoxidized should not be understood as a rigorous chemical oxidereduction status but rather as a general description of sulphide tailings weathering.

The colours of the three identified zones (oxidation zone, hardpan layer and the reduction zone) for H3 drill are presented in Figure 2. 
Data from $\mathrm{H} 2$ and $\mathrm{H} 3$ borehole was combined to produce single weathering characteristics. The weathering profile of Sasar tailing is shown in Figure 3.

It was noted that moisture was increasing from $18 \%$ (a dry state) on surface to $25 \%$ at 2-3 m depth for $\mathrm{H} 1$ and from $20 \%$ on surface to $29 \%$ at $3-4 \mathrm{~m}$ depth on $\mathrm{H} 2$ and $\mathrm{H} 3$, respectively. At 5-6 m depth, the moisture decreases to $12 \%$.

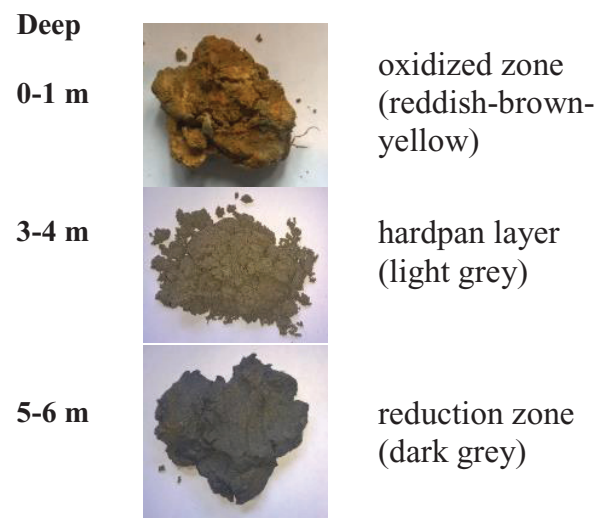

Fig. 2. The colours for oxidation zone, hardpan layer and reduction zone for $\mathrm{H} 3$ drill.

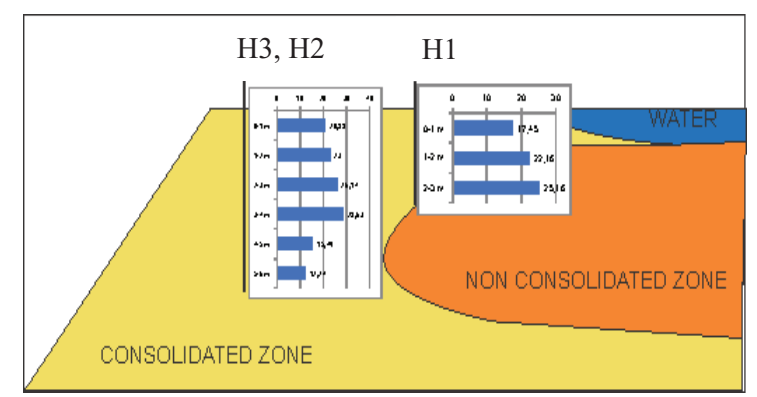

Fig. 3. Weathering profiles for samples $\mathrm{H} 1, \mathrm{H} 2$ and $\mathrm{H} 3$.

\subsection{Physical characteristics of the samples}

From the grain size point of view a decrease of the grain size with depth was noted. The maximum grain size on the surface was 300 microns and 150-250 microns at $6 \mathrm{~m}$ depth.

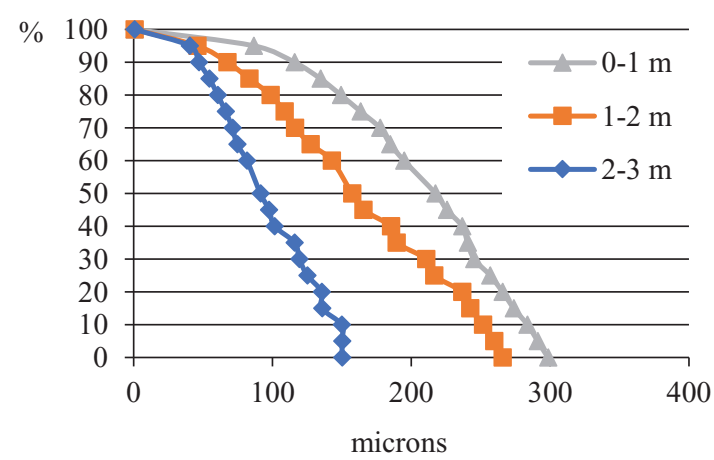

Fig. 4. Grain size distribution of $\mathrm{H} 1$ samples at 0-1m, 1-2 $\mathrm{m}$ and 2-3m depth intervals.

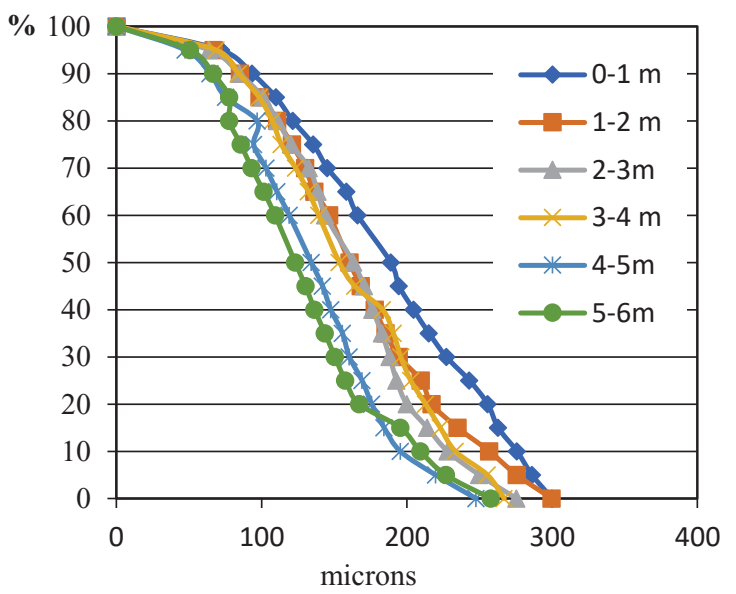

Fig. 5. Grain size distribution of $\mathrm{H} 2$ samples at different depth intervals $(0-1 \mathrm{~m}, 1-2 \mathrm{~m}, 2-3 \mathrm{~m}, 3-4 \mathrm{~m}, 4-5$ and, 5-6m).

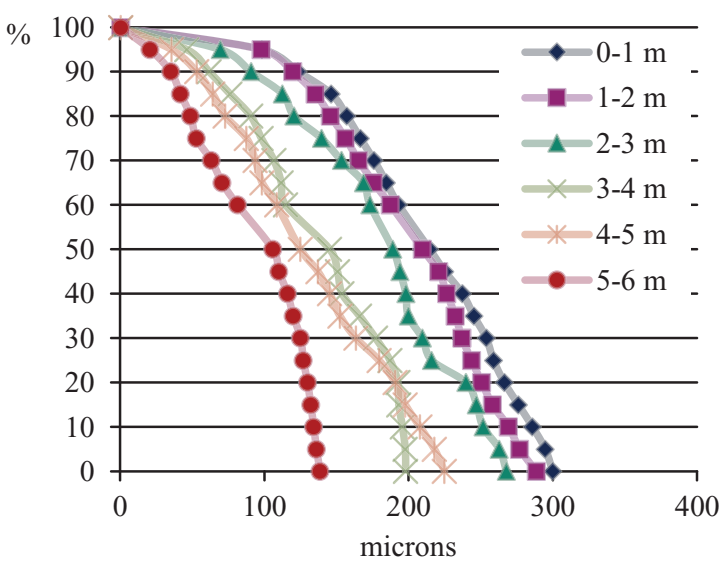

Fig. 6. Grain size distribution of $\mathrm{H} 3$ samples at different depth intervals $(0-1 \mathrm{~m}, 1-2 \mathrm{~m}, 2-3 \mathrm{~m}, 3-4 \mathrm{~m}, 4-5$ and, $5-6 \mathrm{~m})$.

The results presented in Figures 4, 5 and 6 illustrate the variation of grain size distribution of samples with depth.

As a result of the oxidation and weathering of tailings on the surface, a significant decrease of the grain size with depth for all samples was noted. The reduction in $\mathrm{D}_{50}$ with depth is presented in Figures 7, 8 and 9.

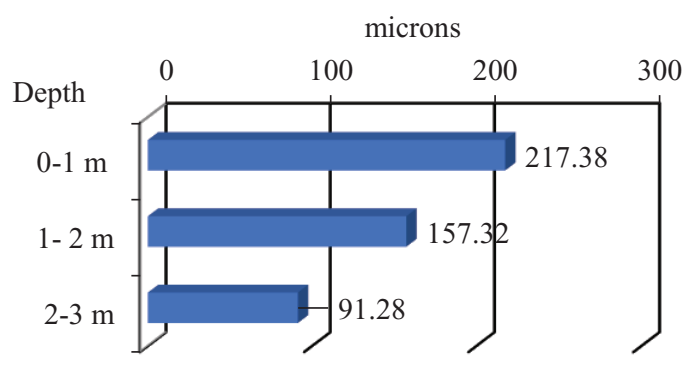

Fig. 7. $\mathrm{D}_{50}$ distribution of $\mathrm{H} 1$ sample. 


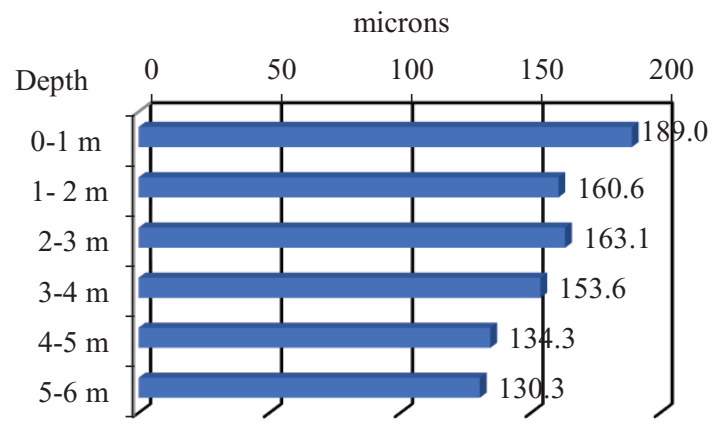

Fig. 8. $\mathrm{D}_{50}$ distribution of $\mathrm{H} 2$ sample.

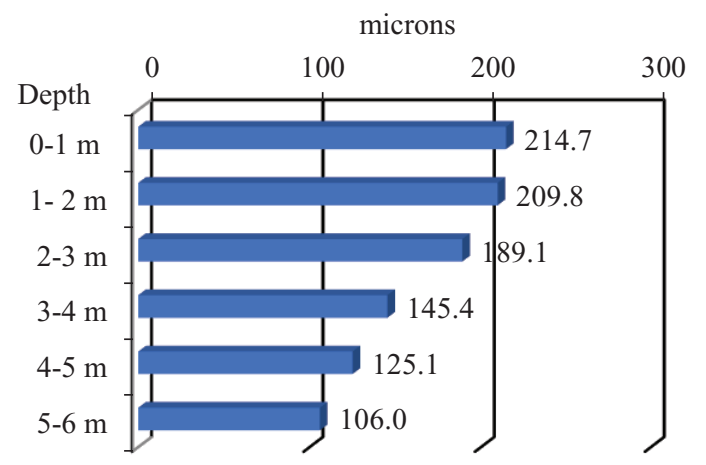

Fig. 9. $\mathrm{D}_{50}$ distribution of $\mathrm{H} 3$ sample.

This fact can be put into account of the sulphide oxidation and acid neutralization processes which entail the breakdown of minerals [26], and the formatting of fine sized weathering products.

\subsection{Geochemical characterization of samples}

Table 1 summarizes the chemical compositions of the tailings samples collected from drill $1(\mathrm{H} 1)$, drill $2(\mathrm{H} 2)$ and drill 3 (H3).

All the tailing samples show exceeding of the heavy metals concentrations, over maximum allowable limit (Annex I A of the Sewage Sludge Directive (86/278/EC)). The total concentrations of elements in the mine tailings were up to $2529 \mathrm{ppm}$ manganese (Mn), $1652.89 \mathrm{ppm}$ zinc $(\mathrm{Zn}), 688.44 \mathrm{ppm}$ lead $(\mathrm{Pb}), 311.50 \mathrm{ppm}$ copper $(\mathrm{Cu})$ and $11.78 \mathrm{ppm}$ cadmium $(\mathrm{Cd})$. The gold and silver content of the tailing samples were $0.45 \mathrm{~g} / \mathrm{t}$ and $4.59 \mathrm{~g} / \mathrm{t}$, respectively.

A size analysis of the samples was performed in order to determine the gold $(\mathrm{Au})$ and silver $\mathrm{Ag}$ ) contents of each size fraction (Table 2).

More than $62 \%$ of the gold were contained in $0.1-0.2$ $\mathrm{mm}$ and $0-0.04 \mathrm{~mm}$ fractions. The $0.1-0.2 \mathrm{~mm}$ fraction contains around $34.67 \%$ of the gold and $19.74 \%$ of the silver in the tailings, while the $0-0.04 \mathrm{~mm}$ fraction contains around $27.67 \%$ of the gold and $54.19 \%$ of the silver.

Gold and silver content distributions in depth for $\mathrm{H} 3$ drill samples are presented in Figure 10.
Table 1. The chemical compositions and average value of elements content in tailings profiles.

\begin{tabular}{|c|r|r|r|r|}
\hline Element & H 1 & H 2 & H 3 & Average \\
\hline $\mathrm{Au} \mathrm{g/t}$ & 0.46 & 0.43 & 0.45 & 0.45 \\
\hline $\mathrm{Ag} \mathrm{g/t}$ & 6.37 & 3.70 & 3.72 & 4.39 \\
\hline $\mathrm{Al} \%$ & 1.64 & 1.01 & 1.03 & 1.23 \\
\hline $\mathrm{As} \mathrm{ppm}$ & 285.67 & 175.00 & 201.67 & 220.78 \\
\hline $\mathrm{B} \mathrm{ppm}$ & 10.00 & 10.00 & 10.00 & 10.00 \\
\hline $\mathrm{Ba} \mathrm{ppm}$ & 120.00 & 165.00 & 146.67 & 143.89 \\
\hline $\mathrm{Ca} \%$ & 1.29 & 1.02 & 0.78 & 1.03 \\
\hline $\mathrm{Cd} \mathrm{ppm}$ & 20.53 & 8.95 & 5.87 & 11.78 \\
\hline $\mathrm{Co} \mathrm{ppm}$ & 10.67 & 9.17 & 6.83 & 8.89 \\
\hline $\mathrm{Cr} p m$ & 27.08 & 16.83 & 14.67 & 19.53 \\
\hline $\mathrm{Cu} \mathrm{ppm}$ & 490.67 & 199.17 & 244.67 & 311.50 \\
\hline $\mathrm{Fe} \%$ & 4.82 & 3.57 & 3.94 & 4.11 \\
\hline $\mathrm{Hg} \mathrm{ppm}$ & 1.33 & 1.33 & 1.17 & 1.28 \\
\hline $\mathrm{K} \%$ & 0.39 & 0.29 & 0.25 & 0.31 \\
\hline $\mathrm{Mg} \%$ & 0.59 & 0.39 & 0.44 & 0.47 \\
\hline $\mathrm{Mn} \mathrm{ppm}$ & 3130 & 2940 & 1517 & 2529 \\
\hline $\mathrm{Mo} \mathrm{ppm}$ & 2.33 & 2.00 & 2.17 & 2.17 \\
\hline $\mathrm{Na} \%$ & 0.03 & 0.02 & 0.02 & 0.02 \\
\hline $\mathrm{Ni} \mathrm{ppm}$ & 13.00 & 9.00 & 4.33 & 8.78 \\
\hline $\mathrm{P} \mathrm{ppm}$ & 440.00 & 365.00 & 413.33 & 406.11 \\
\hline $\mathrm{Pb} \mathrm{ppm}$ & 1029.67 & 490.17 & 545.50 & 688.44 \\
\hline $\mathrm{S} \%$ & 2.81 & 1.79 & 1.64 & 2.08 \\
\hline $\mathrm{Sc} \mathrm{ppm}$ & 5.33 & 3.67 & 3.83 & 4.28 \\
\hline $\mathrm{Sr} \mathrm{ppm}$ & 23.67 & 18.00 & 15.17 & 18.94 \\
\hline $\mathrm{V} \mathrm{ppm}$ & 48.67 & 32.17 & 34.67 & 38.50 \\
\hline $\mathrm{Zn} \mathrm{ppm}$ & 2606.67 & 1451.33 & 900.67 & 1652.89 \\
\hline
\end{tabular}

Table 2. Gold and silver distribution of size fractions.

\begin{tabular}{|c|c|c|c|c|c|}
\hline $\begin{array}{c}\text { Sieve } \\
(\mathbf{m m})\end{array}$ & $\begin{array}{c}\text { Weight } \\
\mathbf{( \% )}\end{array}$ & $\begin{array}{c}\text { Au } \\
\mathbf{( g / t )}\end{array}$ & $\begin{array}{c}\text { Gold } \\
\text { distribu } \\
\text { tion (\%) }\end{array}$ & $\begin{array}{c}\text { Ag } \\
\mathbf{( g / t )}\end{array}$ & $\begin{array}{c}\text { Silver } \\
\text { distribu } \\
\text { tion (\%) }\end{array}$ \\
\hline$>0.2$ & 13.33 & 1.125 & 33.31 & 4.2 & 12.75 \\
\hline $0.1-0.2$ & 34.67 & 0.225 & 17.32 & 2.5 & 19.74 \\
\hline $0.075-0.1$ & 12.67 & 0.26 & 7.22 & 2.50 & 7.21 \\
\hline $0.04-0.075$ & 11.67 & 0.26 & 6.76 & 2.30 & 6.11 \\
\hline $0-0.04$ & 27.67 & 0.576 & 35.39 & 8.6 & 54.19 \\
\hline & 100 & 0.45 & 100.00 & 4.39 & 100.00 \\
\hline
\end{tabular}

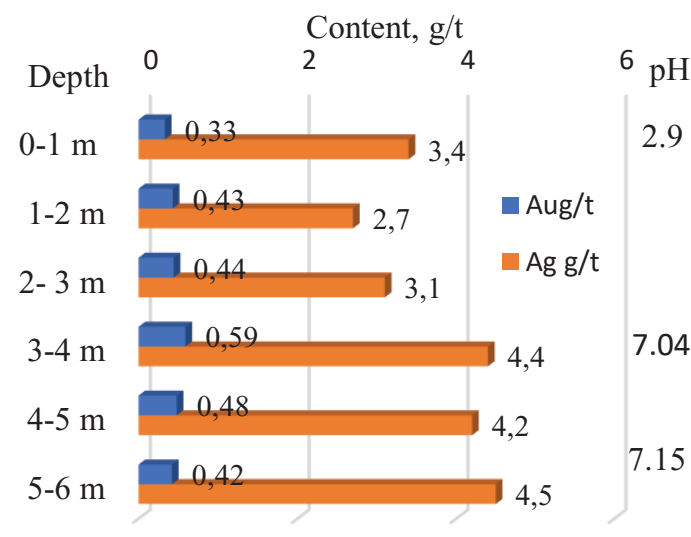

Fig. 10. Gold and silver content distributions in depth for $\mathrm{H} 3$ drill samples. 
The obtained data showed a low content of gold and silver in oxidation zone, $0-1 \mathrm{~m}(\mathrm{pH}=2.9)$. The metals from oxidation zone accumulated in hardpan layer $(\mathrm{pH}=7.04)$ where the highest content can be seen (3-4 m depth). The reduction zone $(\mathrm{pH}=7.15)$ was located in 5-6 $\mathrm{m}$ depth interval.

Calcium (Ca), iron (Fe) and sulphur (S) content distributions in depth for $\mathrm{H} 3$ drill are presented in Figure 11.

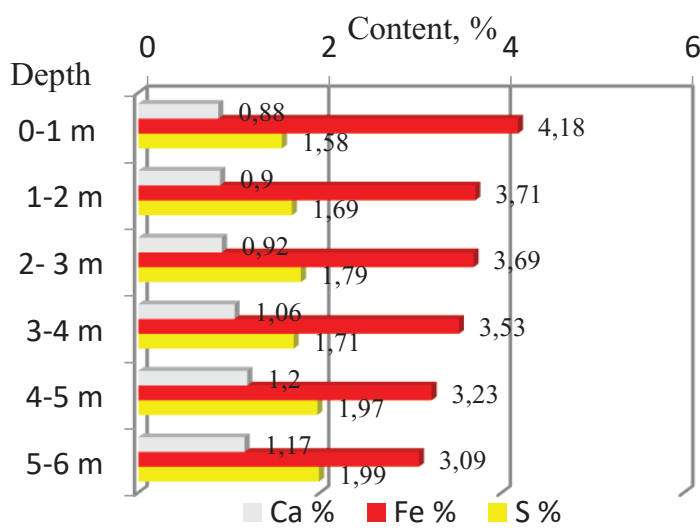

Fig. 11. Calcium, iron and sulphur content distributions in depth for $\mathrm{H} 3$ drill core.

In oxidation zone $(\mathrm{pH}=2,9)$ the lowest contents of $\mathrm{Ca}$ and $\mathrm{S}$ and the highest content of $\mathrm{Fe}$ can be noted. In this volume, the carbonate minerals are dissolved and the sulphides are oxidised.

The obtained data showed that the $\mathrm{Ca}$ content increases from $0.88 \%$ in oxidation zone $(\mathrm{pH}=2.9)$ to $1.17 \%$ in the reduction zone $(\mathrm{pH}=7.15)$ and the $\mathrm{S}$ content increases from $1.58 \%$ in oxidation zone $(\mathrm{pH}=2.9)$ to $1.99 \%$ in the reduction zone $(\mathrm{pH}=7.15)$. The Fe content decreases with depth from $4.18 \%$ in oxidation zone to $3.09 \%$ in reduction zone.

As Sasar tailing impoundment has high average grades of gold and silver, its reprocessing could be considered as an economically feasible possibility.

\subsection{Static tests results}

The static geochemical tests were performed on pulverized $(<75 \mu \mathrm{m})$ samples collected from $\mathrm{H} 3$ drill from $1 \mathrm{~m}, 3 \mathrm{~m}$ and $6 \mathrm{~m}$ depth.

\subsubsection{Paste $p H$}

Table 3 provides data related to paste $\mathrm{pH}$ and electric conductivity of samples. Samples D1, D3 and D6 were collected from $\mathrm{H} 3$ drill, at $1 \mathrm{~m}, 3 \mathrm{~m}$ and $6 \mathrm{~m}$ depth respectively.

Table 3. Paste $\mathrm{pH}$ and electric conductivity.

\begin{tabular}{|c|c|c|c|}
\hline Sample & Time, $\mathbf{h}$ & $\mathbf{p H}_{\mathbf{1 : 2}}$ & $\left.\mathbf{E C}_{\mathbf{1 : 2}} \mathbf{(} \boldsymbol{\mu S} \mathbf{S} \mathbf{c m}\right)$ \\
\hline \multirow{2}{*}{ D1 } & 1 & 2.87 & 351 \\
\cline { 2 - 4 } & 12 & 2.93 & 638 \\
\hline \multirow{2}{*}{ D3 } & 1 & 7.02 & 1080 \\
\cline { 2 - 4 } & 12 & 7.06 & 1466 \\
\hline \multirow{2}{*}{ D6 } & 1 & 7.11 & 654 \\
\cline { 2 - 4 } & 12 & 7.18 & 1710 \\
\hline
\end{tabular}

D1 sample showed a paste $\mathrm{pH}$ below 4 and an electrical conductivity $>20 \mu \mathrm{S} / \mathrm{cm}$, meaning that it contains a high amount of dissolved salts. As a consequence, the D1 sample could be included in the category of samples with acid generation potential.

The values of $\mathrm{pH}$ over 7 obtained in the case of $\mathrm{D} 3$ and D6 samples indicate that those can either be potentiallyacid-forming or non-acid forming, depending on their acid-base balance.

\subsubsection{Acid-Base Accounting}

Net acid production potential (NAPP) data, including acid neutralization capacity (ANC) and maximum potential acidity (MPA) and ANC to MPA ratio, is provided in Table 4.

Table 4. Acid - base account data for waste sample.

\begin{tabular}{|c|c|c|c|c|c|c|c|}
\hline \multirow[t]{2}{*}{ Sample } & \multirow[t]{2}{*}{ Fizz rate } & \multirow{2}{*}{$\begin{array}{c}\text { HCl } \\
\text { Vol } \\
(0.5 \mathrm{M}) \mathrm{mL} \\
\end{array}$} & \multirow{2}{*}{$\begin{array}{c}\mathrm{S} \\
(\%) \\
\end{array}$} & ANC & MPA & NAPP & \multirow{2}{*}{$\begin{array}{l}\text { ANC } \\
\text { /MPA }\end{array}$} \\
\hline & & & & \multicolumn{3}{|c|}{$\left(\mathrm{kg} \mathrm{H}_{2} \mathrm{SO}_{4} / \mathrm{t}\right)$} & \\
\hline D1 & 0 & 4 & 0.46 & -1.81 & 14.10 & 15.89 & -0.13 \\
\hline D3 & 1 & 8 & 1.71 & 5.77 & 52.33 & 46.56 & 0.11 \\
\hline D6 & 2 & 20 & 2.05 & 62.3 & 62.73 & 0.43 & 0.99 \\
\hline & & & & $\begin{array}{l}\text { tions: } \\
6 \mathrm{x} \% \mathrm{~S} \\
\text { P-AN }\end{array}$ & & & \\
\hline
\end{tabular}

A sample is classified as potentially acid forming (PAF) when NAPP has positive values. In addition, the ANC to MPA ratio of the samples were less than 1, which classified them as "possibly" or "likely acid generating" materials. [26] In our case study, the obtained net acid production potential (NAPP) values were positive, which indicated that the samples were potentially acid forming materials.

\subsubsection{Single addition NAG test}

The single addition net acid generating (NAG) test was used to assess the validity of NAPP predictions. Using NAG test in conjunction with ABA methods to classify the samples, can reduce the risks of misclassifying nonacid forming samples (NAF) as potentially acid forming (PAF) and PAF material as NAF. Table 5 shows ABA (NAPP) and NAG results of the samples. 
Table 5. NAPP and NAG test results for D1, D3 and D6 samples.

\begin{tabular}{|c|c|c|c|c|c|}
\hline Sample & NAGpH & $\begin{array}{c}\text { NAG } \\
\text { pH4.5 }\end{array}$ & NAG & NAPP & $\begin{array}{c}\text { ARD } \\
\text { Classification }\end{array}$ \\
\cline { 3 - 5 } & & \multicolumn{3}{|c|}{$\left.\mathbf{( k g H 2 S O}_{4} / \mathbf{t}\right)$} & \\
\hline D1 & 3.17 & 3.43 & 6.56 & 15.885 & PAF \\
\hline D3 & 2.55 & 24.30 & 29.79 & 46.556 & PAF \\
\hline D6 & 2.70 & 11.95 & 17.05 & 0.430 & PAF \\
\hline
\end{tabular}

A standard classification scheme [22] is used to present this data (Fig. 12), which compares NAG pH to NAPP and identifies non-acid forming samples from potentially-acid forming samples. Potentially acid forming (PAF), non-acid forming (NAF) and uncertain (UC) classification domains are indicated.

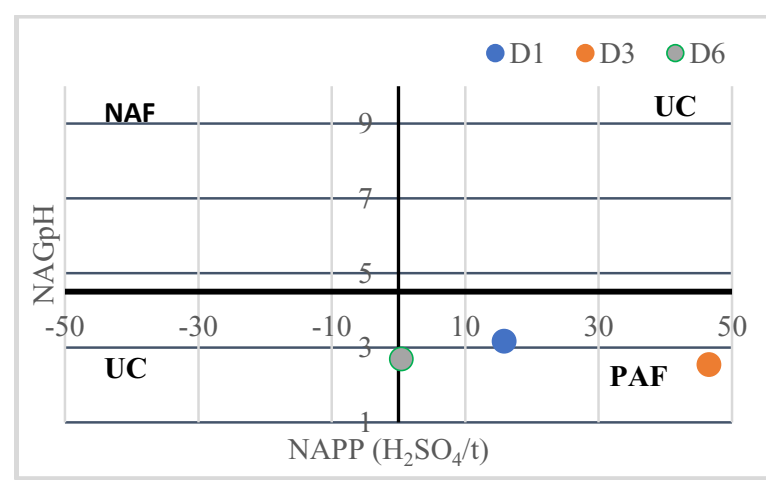

Fig. 12. ARD classification plot for a case study sample set.

A sample is classified as PAF when it has a positive $\mathrm{NAPP}$ and $\mathrm{NAGpH}<4.5$, and NAF when it has a negative NAPP and NAGpH $\geq 4.5$. Samples are classified uncertain when there is an apparent conflict between the NAPP and NAG results, i.e. when the NAPP is positive and $\mathrm{NAGpH} \geq 4.5$, or when the NAPP is negative and $\mathrm{NAGpH}<4.5$. [22]

The NAPP results obtained compared with NAG results confirmed that samples would produce acidity upon exposure to oxygen and water.

\section{Conclusions}

Providing long term access to the available mineral resources therefore requires more focus on sustainable mining, both on research for environmentally sound mining and processing technology, as well as on the social and economic aspects of mining.

To counteract the steady increase in global demand for primary mineral resources and to reduce the negative social and environmental impacts associated with meeting this demand, it is necessary to increase material efficiency in manufacturing processes, to search for new substitute raw materials and to recycle materials more widely and more effectively, through technological innovations. Reprocessing of mining wastes, prioritizing those with acute environmental impacts, is a way to improve this metal recovery while protecting human being and the environment.
Tailings from mineral processing of polymetallic ore stored in Sasar (Red Valley) impoundments, located in the western part of Baia Mare (Romania), were characterized by grain size, elemental composition, elements distribution in depth and potential of ARD generation. The main conclusions related to this study can be summarized as follows:

-The results have indicated that tailings exhibit very high level of metal content, especially with $\mathrm{Mn}, \mathrm{Zn}, \mathrm{Pb}$, $\mathrm{Cu}$, exceeding the standards for soil, thus, gold mine tailings can be considered as a potential primary source of soil and groundwater contamination in mining areas

- The gold and silver content of the tailing samples were $0.45 \mathrm{~g} / \mathrm{t}$ and $4.59 \mathrm{~g} / \mathrm{t}$, respectively, reprocessing of tailing could be considered as an economically feasible possibility;

-Comparison of NAG and NAPP results demonstrated the effectiveness of the NAG test in highlighting potential issues in $\mathrm{ABA}$ predictions;

-Both the modified ABA and the NAG test classified the samples into the category of 'potentially acid generating'.

This work was funded under the scope of the "3rd ERA-MIN Joint Call (2015) on Sustainable Supply of Raw Materials in Europe" by a grant of the Romanian National Authority for Scientific Research and Innovation, CCCDI - UEFISCDI, project: Improve Resources Efficiency and Minimize Environmental Footprint - REMinE, Contract no.13/2016. Coordinator: Luleå University of Technology (LTU), Sweden; Partners: Research and Development National Institute for Metals and Radioactive Resource, Romania, University of Porto, Portugal.

\section{References}

1. G. Morteani, J. P. Northover, Proceedings of the NATO advanced research workshop on prehistoric gold in Europe. Germany. 136. (Kluwer Academic Publishers 1993)

2. Gh.C. Popescu, Geol.and Seism. Inst. Bull. ASM. N1. (2015)

3. G. B. Lottermoser, Mine wastes. Characterization. treatment and environmental inpacts. 3rd Ed. Springer. 253-254. (2010)

4. C. Modoi, S.N. Vlad, I.C. Stezar, D. Manciula, A.C. Gagiu. S. Marginean. Environ Eng Man J., 10, 43-51 (2011)

5. D.W Blowes. CJ. Ptacek. J.L. Jambor, C.G. Weisener in H.D. Holland, K.K. Turekian, Treatise on geochemistry. (Elsevier. Oxford., 149-204, 2003)

6. K.D. Nordstrom, C.N Alpers,. Rev Econ Geol 6A, 133-160 (1999)

7. T. Rösner, A. van Schalkwyk. Bull Eng Geol Env.(Q Springer-Verla) 59, 137-148 7 (2000)

8. H. Bouzahzah. M. Benzaazoua. B. Bussiere, B. Plante, Mine Water Environ. 33, 54-65 (2014)

9. A.K. Kourtis, B. Gazea, A. Kontopoulos, Trans Inst Min Metall A 106, A1-A8 (1997) 
10 D.W. Duncan, A. Bruynesteyn, Proceedings of the metallurgy soc AIME. paper A79-29 (1979)

11. K. Lapakko, Proceedings of the international land reclamation and mine drainage conference and $3 \mathrm{rd}$ ICAR. Pittsburg. USA, 1, 129-137 (1994)

12. J. Skousen, J. Simmons, L.M. McDonald, P. Ziemkiewicz, J Environ Qual, 31, 2034-2044 (2002)

12. AA. Sobek, W.A. Schuller, J.R. Freeman, R.M Smith, EPA-600/2-78-054, 47-50 (1978)

13. P.A. Weber, J.E. Thomas, W.M. Skinner, R.S.C. Smart, Appl Geochem 19, 687-694 (2004)

14. P.A. Weber, J.E. Thomas, W.M. Skinner, R.S.C. Smart. Can Mineral 43, 1183-1192 (2005)

15. J.L. Jambor, J.E. Dutrizac, M. Raudsepp, Environ.Geol. 52, 1019-1031 (2007)

16. A.S. Warwick, D.M. Stuart, R. Smart, Proceedings od the 7th International Conference on Acid Rock Drainage (ICARD) (2006)

17. I. Mac, General Geography. (in Romanian). Europontic Press. Cluj-Napoca, Romania (2000)
18. V. Mutihac Technical Press. Bucharest. Romania (1990)

19. F. Benciu, Did.and Ped. Publish. House. Bucharest. Romania (2007)

20. AMIRA P387A, I. W. Res.Inst. Env. Geochem. Int. Pty Ltd, A-5 (2002)

21. J.G. Crock, B.F. Arbogast, P.J. Lamothe, In: G.S. Plumlee, M.J. Logsdon, Reviews in Economic Geology, 6A, 264-287(Chapter 13) (1999)

22. R.W. Lawrence, P.B. Marchant. MEND Project 1.16.1b. CAMNET. Ottawa (1989)

23. J.L. Jambor, J.E. Dutrizac, M. Raudsepp. L.A. Groat, J.Environ Qual 32, 2373-2378, (2003).

24. B. Dold, L. Fontboté, J. of Geochem. Expl.74, 3-55, (2001)

25. M.J. Brodie, L.M. Broughton. A. MacG. Robertson, Proceedings of the second international conference on the abatement of acidic drainage, 1 - 4, Montreal, Canada. (1991) 